\title{
II CONGRESO FEDERAL DEL PARTIDO DEMOCRATA LIBERAL
}

El II Congreso Federal del Partido Demócrata Liberal, celebrado en Madrid durante los días 20 y 21 de enero del presente año, ha suscitado un vivo iṇterés, y en ello ha influido sin duda la llamada «operación reformista», que tiene como máximos promotores al propio presidente del Partido Demócrata Líberal, Antonio Garrigues, y al líder nacionalista catalán, Miguel Roca.

Los compromisarios asistentes a. este Congreso han tenido como misión principal aprobar los Estatutos y el programa político que regirán hasta la proyectada disolución del Partido Demócrata Liberal, como formación política autónoma, y su consiguiente integración en el futuro Partido Reformista, cuya creación está proyectada, en principio, para el próximo mes de mayo.

La aparición en la escena política de este nuevo partido, de carácter reforimista, estaría avalada, en opinión de sus promotores, por la necesidad de llenar un espacio entre lo que los propios promotores denominan el «autoritarismo conservador» y el «dogmatismo socialista». Un espacio, obviamente, de centro, que debe llenarse con un liberalismo reformista, toda vez que las tendencias socialdemócratas han sido acaparadas por el Partido Socialista Obrero Español y las democristianas están integradas en la actual Coalición Popular.

Por otra parte, este espacio electoral entre las dos fuerzas políticas mayores en la actualidad está perfectamente definido y tiene, en opinión de los defensores de esta operación reformista y en la nuestra propia, unos votos concretos en el país.

De esta manera, el Partido Demócrata Liberal, o aquel otro partido en el que éste se integre, servirá principalmente para romper la bipolarización existente, el bipartidismo, a nivel nacional, que ha ocasionado que un no poco despreciable número de ciudadanos hayan tenido que acomodar su propia tendencia política a las opciones útiles existentes en cada momento.

Por otro lado, y antes de entrar, aunque sea brevemente, en el contenido de este II Congreso Federal, queremos destacar la importancia que, en todo caso, tiene una operación como la que se está gestando, cuya principal característica no es sólo articularse en torno a una idea de centro -en este caso, un centrismo liberal y reformista-, sino hacerlo incorporando tendencias específicamente nacionalistas, en principio, del nacionalismo catalán. Pensamos que si se llega a consolidar un centro que además integre algunos sectores nacionalistas, su importancia política y su eventual ascenso electoral estarían muy claramente avalados.

Pero, en concreto, este II Congreso Federal del Partido Demócrata Liberal ha 
definido su organización y sus principios básicos que, como hemos dicho antes y según todas las predicciones, regirán hasta su integración en una nueva formación política.

\section{A) La organización del partido}

La estructura del Partido Demócrata Liberal es de carácter federal y está organizada en partidos de ámbito territorial coincidente con el de las Comunidades Autónomas que integran el Estado español.

El organigrama funcional básico del Partido Demócrata Liberal es el que se indica en gráfico de la página siguiente.

\section{B) Principios ideológicos y actuación política}

Sus principios ideológicos son, en general, los defendidos por el liberalismo tradicional, haciéndose especial hincapié en la libertad individual y en la persona como eje de la organización social, o como el propio Partido Demócrata Liberal afirma: «El respeto a la persona humana, la defensa de las libertades individuales y la igualdad de oportunidades entre personas libres y solidarias» (art. 2.0 de los Estatutos del partido).

Su actuación política, como ya hemos dicho antes, se enclavaría en un espacio intermedio entre las dos fuerzas políticas que actualmente monopolizan, de alguna manera, el poder a nivel nacional, intentando instalar, en definición propia, la eficacia gestora, la modernización del Estado y un sentido profundo de la libertad que respete y fomente la espontaneidad social.

A pesar de las grandes declaraciones a favor de la libertad individual, el Partido Demócrata Liberal es consciente de la necesidad de adecuar los postulados tradicionales del liberalismo a las circunstancias actuales y, especialmente, a las enseñanzas históricas; por ello aceptan como necesario un pacto entre el individuo y la sociedad, la cual deberá crear las condiciones para que la libertad del propio individuo sea realmente posible.

Por otro lado, destaca, junto al concepto de libertad, del que ya hemos hablado, el de igualdad de oportunidades. Esta expresión, igualdad de oportunidades, que formulan los liberales, vienen a expresar la idea de que todos los hombres no son iguales objetivamente considerados, aunque sí tienen todos el mismo valor, de ahí que la igualdad que debe regir entre ellos es la igualdad de poder alcanzar las mismas cotas, es decir, la igualdad de oportunidades para cualquier actividad social.

\section{C) La intervención del Estado}

Como es sabido, el postulado liberal acerca de la intervención estatal en la sociedad y la política es restrictivo; así, en los principios básicos que marca el Partido Demócrata Liberal en torno a las relaciones «individuo-Estado» se encuentra la defensa de «un Estado mínimo que mantenga la libertad individual y política de sus miembros».

De igual manera esta limitación de la intervención estatal se hace sentir en los postulados económicos. Se propugna abiertamente el cese del incremento de la participación del sector público en los escasos recursos disponibles, tanto fiscales como financieros. Resulta, para el Partido Demócrata Liberal, imprescindible devolver al sector privado español la confianza en su capacidad creativa y los recursos necesarios para desarrollarla. 
ORGANIGRAMA FUNCIONAL BASICO DEL PARTIDO DEMOCRATA LIBERAL

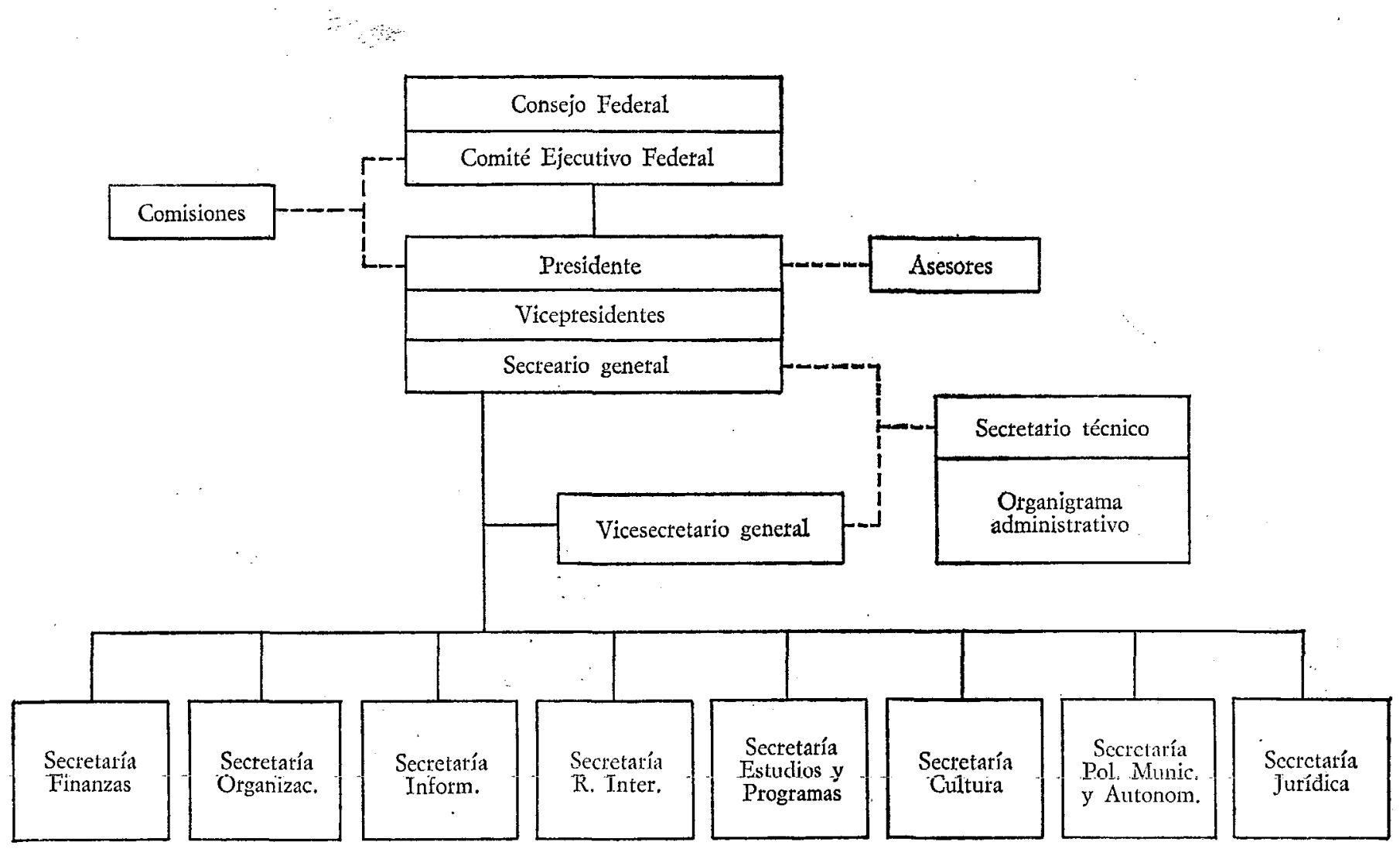


La economía del futuro deberá tener, en opinión de este Partido Liberal, la suficiente flexibilidad para adaptarse a las rápidas mutaciones que la «sociedad de la información» producirá en todas las sociedades.

En síntesis, su éstrategia económica se basa en:

- Restablecer el protagonismo de los ciudadanos y la competencia.

- Aumentar la productividad de los factores económicos y nuestra competitividad exterior.

- Fomentar el nacimiento de nuevas empresas y el desarrollo de las existentes.

\section{D) Política exterior}

La política internacional, para el Partido Demócrata Liberal, se basa principalmente en una serie ordenada y coherente de acciones que configuren una estrategia clara de nuestra postura frente a los grandes problemas internacionales. Básicamente, los principios en que debería apoyarse la política internacional española son:

- Una definición claramente occidentalista de España.

- Intensificación del proceso de integración de España en la Comunidad Económica Europea.

- Permanencia de nuestro país en la OTAN.

- Reivindicación continuada de Gibraltar como territorió español.

- Reactivación de las relaciones con los países iberoamericanos.

\section{E) Los Estatutos del partido}

Uno de los aspectos más destacables de los Estatutos aprobados en este II Congreso Federal del Partido Demócrata Liberal, teniendo siempre como fondo la 1lamada «operación reformista», de la que antes hemos hablado, se encuentra en el artículo 32, en el que se contempla la posibilidad de la disolución del Partido por acuerdo del Congreso Federal, que podrá, a su vez, delegar esta facultad en el Consejo Federal, posibilidad que hay que entender acogida para llevar a cabo, en su caso, la creación de la nueva formación política de carácter reformista.

\section{F) Conclusiones}

Un Congreso, en suma, que ha ratificado los postulados liberales, pero que ha acogido, a la vez, todas las matizaciones que esta ideología política y social precisa para articularse en las democracias occidentales. El Partido Demócrata Liberal ha presentado en este II Congreso Federal un amplio y muy elaborado programa de actuación, que contiene, sin duda, interesantes aspectos, sin que en ningún momento se hayan obviado los grandes problemas que afectan a nuestro país tanto a nivel interno como en el campo internacional.

Yolanda Gómez SÁnchez

Fuente: Material e información aportados por el Partido Demócrata Liberal en Madrid. 